\title{
Comparison of clinical and cognitive characteristics of a Mexican adult clinical population with and without ADHD
}

Palacios-Cruz L., ' Galicia F., ${ }^{2}$ Arias-Caballero A., ${ }^{2}$ Cárdenas Godínez EM., 'Vásquez-Medina J., ${ }^{2}$ Mayer-Villa P., ${ }^{3}$ Feria Aranda M., ${ }^{2}$ Cruz-Fuentes C., ${ }^{1}$ De la Peña F., ${ }^{4}$ Ulloa Flores RE., ${ }^{3}$ Rosetti M., ${ }^{5}$ Reyes-Zamorano E., ${ }^{6}$ Nafate O., Fragoso A., ${ }^{8}$ Ortiz S., 9 Jaimes A., 9 Garza Gallegos K., ${ }^{2,10}$ Lara-Muñoz MC. 11

Subdirección de Investigaciones Clínicas, Instituto Nacional de Psiquiatría Ramón de la Fuente Muñíz, Ciudad de México, México.

Subdirección de Consulta Externa, DirecSubdirección de Consulta Externa, Dirección de Servicios Clinicos, Instituto $\mathrm{Na}$ cional de Psiquiatría Ramón de la Fuente Muñíz, Ciudad de México, México.

Departamento de Psicofarmacología del Desarrollo, Hospital Psiquiátrico Infantil Juan N. Navarro, Ciudad de México,

México.

Departamento de Fomento a la Investigación, Dirección de Servicios Clínicos, Instituto Nacional de Psiquiatría Ramón de la Fuente Muñíz, Ciudad de México, México.

Instituto de Investigaciones Biomédicas, Universidad Nacional Autónoma de México, Ciudad de México, México.

México, Ciudad de México, Mexico.

Departamento de Investigaciones en Psicología y Salud Mental, Universidad Anáhuac del Sur, Ciudad de México, México.

Clínica de Salud Mental del Hospital de Especialidades Pediátricas, Tuxtla Gutierrez, Chiapas, México.

8 Facultad de Ciencias, UNAM, Ciudad de México, México.

Departamento de Psiquiatría y Salud Mental, Facultad de Medicina, Universidad Nacional Autónoma de México, Ciudad de México, México.

- Facultad de Psicología, Universidad de Londres, Ciudad de México, México.

Facultad de Medicina Benemérita, Universidad Autónoma de Puebla, Puebla, México.

\section{Correspondence:}

Palacios-Cruz, L.

Subdirección de Investigaciones Clínicas, Instituto Nacional de Psiquiatría Ramón de la Fuente Muñíz.

Calz. México-Xochimilco 101, Col. San Lorenzo Huipulco, Del. Tlalpan, C.P. 14370, Ciudad de México, México. Phone: +52 55 5407-1910 Email: lino.palacios@salud-mental.org.mx

Received: 6 September 2018

Accepted: 5 December 2018

Citation:

Palacios-Cruz, L., Galicia, F., Arias-Caballero, A., Cárdenas Godínez, E. M., Vásquez-Medina, J., Mayer-Villa, P. ... LaraMuñoz M. C (2018). Comparison of clinican cal and cognifive characteristics of a Mexican adult clinical population with and without ADHD. Salud Mental, 41 (6), 297-305. doi: 10.17711/SM.0185-3325.2018.042 (cc) (P) $\$$

\begin{abstract}
Introduction. Attention deficit hyperactivity disorder (ADHD) is a neurodevelopmental disorder affecting approximately $5 \%$ of the world population, with symptoms that may persist into adulthood. Despite the findings on the clinical course of this disorder, information regarding comorbidity patterns, psychosocial and executive functioning in adult life in those with and without ADHD in Latin American samples is scarce. Objective. The aim of this study is to compare the comorbidity pattern, psychosocial, and executive functioning of adults with and without ADHD from a clinical sample. Method. One hundred and fifty-one patients between 20 and 45 years, with screened positively on ASRS-V1.1, were invited to continue an evaluation process as part of clinical research program (PROMETEO): 1) K-SADS-PL Mx interview, 2) MINI-Plus interview, ASRS-V1-1 18 item version, BRIEF self-reported questionnaire, SCQA-ADHD, and 3) Individual case review by clinical expert in ADHD. Results. Individuals in the ADHD group had a higher average of comorbid disorders (2.5 SD 1.1 vs. $1.3 S D 1.0$ respectively, $F=.439 ; t=-6.621 ; d f=149 ; p<.001)$, more likelihood of procrastinating $(O R=6.5$; $95 \% \mathrm{CI}[2.6,16.2] ; z=4.0)$ and were more likely to present difficulties in both the behavior regulation index $(O R=104.9 ; 95 \% \mathrm{Cl}[31.8,345.7] ; z=7.65)$ and the metacognitive index $(O R=94.79 ; 95 \% \mathrm{Cl}[29.10,308.76]$; $z=7.56$ ) compared to the non-ADHD group, regardless of gender. Discussion and conclusions. Our results indicate that the ADHD adult group presented with more comorbidity, and worse psychosocial and executive functioning than non-ADHD adults.
\end{abstract}

Keywords: ADHD, adult, women, comorbidity, executive functions.

\section{RESUMEN}

Introducción. El trastorno por déficit de atención con hiperactividad (TDAH) es un trastorno del neurodesarrollo que afecta aproximadamente al $5 \%$ de la población mundial, persistiendo hasta la adultez. A pesar de los hallazgos acerca del curso clínico de este trastorno, la información es escasa con respecto a los patrones de comorbilidad, funcionamiento psicosocial y ejecutivo en la vida adulta entre aquellos con y sin TDAH en muestras latinoamericanas. Objetivo. Comparar el patrón de comorbilidad, el funcionamiento psicosocial y ejecutivo de adultos con y sin TDAH de una muestra clínica. Método. Ciento cincuenta y un pacientes entre 20 y 45 años, quienes inicialmente presentaron un tamizaje positivo del ASRS-V1.1, fueron evaluados dentro de un programa de investigación clínica (PROMETEO) con los siguientes instrumentos: 1) la entrevista K-SADS-PL-Mx, 2) la entrevista MINI-Plus, la version de 18 items del ASRS-V1-1, y los cuestionarios autoaplicados BRIEF y SCQA-ADHD y 3) Revisión de cada caso por un clínico experto en el diagnóstico de TDAH. Resultados. El grupo de TDAH comparado con aquel sin TDAH presentó un mayor promedio de trastornos comórbidos (2.5 DE 1.1 vs $1.3 D E 1.0$ respectivamente, $F=.439 ; t=-6.621 ; g l=149 ; p<.001$ ), mayor probabilidad de procrastinar $(O R=6.5 ; 95 \% \mathrm{IC}[2.6,16.2] ; z=4.0)$, y mayor probabilidad de presentar dificultades tanto en el índice de regulación de la conducta $(O R=104.9 ; 95 \% \mathrm{IC}[31.8,345.7] ; z=7.65)$ como en el índice metacognitivo $(O R=94.79 ; 95 \% \mathrm{IC}[29.10,308.76] ; z=7.56)$ independientemente del sexo. Discusión y conclusión. Nuestros resultados señalan que los adultos con TDAH presentan mayor comorbilidad y peor funcionamiento psicosocial y ejecutivo que los adultos $\sin T \mathrm{TAH}$.

Palabras clave: TDAH, adulto, mujeres, comorbilidad, funciones ejecutivas. 


\section{INTRODUCTION}

Attention deficit hyperactivity disorder (ADHD) was recently incorporated into the neurodevelopmental disorder category. It is considered one of the main reasons for mental health consultation in children and adolescents (Biederman, 2005; Langley et al., 2010; Polanczyk et al., 2008). Epidemiological studies indicate that approximately $5.29 \%$ of the general population at any stage of life has this disorder (Polanczyk, de Lima, Horta, Biederman, \& Rohde, 2007). The sex ratio distribution for men and women varies. In community samples, it has a 2 to 1 distribution and in clinical samples a larger difference is observed with a 9 to 1 distribution, with men appearing to be more affected in both cases (Biederman \& Faraone, 2005; Polanczyk et al., 2007; Polanczyk \& Rohde, 2007). The National Comorbidity Survey Replication (NCR-R) conducted in the United States (Kessler et al., 2006) showed that, in adults, the presence of ADHD is a marker of poor prognosis for the presence of comorbidity and from an earlier age of onset.

In the middle of the last century, studies on this disorder focused on the child population, since it was assumed that ADHD did not manifest in adulthood (Ramos-Quiroga et al., 2006). This perspective has gradually changed, and it is currently thought that a significant proportion of children affected by this disorder persist into adult life and have associated impairment during adulthood (Barkley, 2008; Biederman, 1998; Biederman et al., 1996; Matte, Rohde, \& Grevet, 2012). Both the DSM-5 and the International Classification of Diseases 11th revision (ICD 11) have tried to capture the clearest clinical presentation of ADHD in adults in various contexts, mainly the clinical one (Faraone et al., 2006; Kessler et al., 2010; Matte et al., 2012).

Recent reports by longitudinal studies indicate that although ADHD persists into adulthood, it has not been observed in the expected proportion, Moffit et al. (2015) recently noted that $90 \%$ of adult ADHD cases lacked a history of childhood ADHD. Thus, ADHD may display different trajectories in its clinical presentation (Agnew-Blais et al., 2016; Asherson, Buitelaar, Faraone, \& Rohde, 2016; Caye et al., 2016; Matte et al., 2012; Moffitt et al., 2015). The symptomatic expression of ADHD, including adulthood onset ADHD, depends on the context, in other words, the interaction between biological aspects such as neurocognitive resources and environmental aspects such as the familial, interpersonal, academic and work spheres in which the affected subjects develop (Lasser, Goodman, \& Asherson, 2012). Other factors such as sex, age at the time of evaluation, differences in definitions of impairment or context (e. g., urban vs. sub-urban, traditional vs. non-traditional school, etc.) are known to influence the presentation of ADHD.

Nevertheless, scientific evidence published in recent years on adults with ADHD, highlights the lack of its rec- ognition among mental health care professionals, probably associated with difficulties in its understanding and conceptualization. Errors and omissions in ADHD often prevent those affected from receiving timely and effective treatments for their condition, which ultimately leads to unnecessary health and general life consequences (Kooij et al., 2010).

Although there is scientific information about adults with ADHD in a clinical context of developing countries, as in the case of Mexico (Almeida et al., 2006; Fayyad et al., 2007"; Lara et al., 2009), we know very little about the implications of having ADHD in a Latin American clinical sample, or the relationship between executive functioning and ADHD in adulthood. It is for this reason that we decided to study a sample of adults in a clinical context who have ADHD compared with non-ADHD adults.

\section{METHOD}

Once the project had been approved by the corresponding scientific and ethics committees of the Instituto Nacional de Psiquiatría Ramón de la Fuente Muñiz (INPRFM), and after informed consent had been obtained, the sample included male and female adults ages 20 to 45, who voluntarily requested psychiatric medical care at the INPRFM. Participants were invited to the Clinical Research Program on lifetime ADHD (PROMETEO), a clinical research and human resource training initiative implemented since 2007, if they had less than one week of treatment and could read and write, so that they could be interviewed and complete the clinimetric instruments. All the subjects who completed the evaluations were included.

This clinical research program evaluation process was carried out in three stages, after respondents had answered the short, six-item version of the Adult Self Reported Scale ASRS V1.1. If they displayed at least three of the six positive items (Adler et al., 2006) or had a score of over 10 points (Ramos-Quiroga et al., 2009), they were invited to participate in the first stage of this clinical program. During this stage, diagnosis was confirmed by a clinician with at least five years' experience using the Spanish version of Kiddie Schedule for Affective Disorders and Schizophrenia present and lifetime (K- SADS- PL) with DSM-IV criteria. Comorbid disorders were then evaluated in a second stage through the MINI International Neuropsychiatric Interview (M.I.N.I.). In addition to the interview, symptom severity was obtained from the ASRS-V1.1, 18-item version and executive functions were assessed through the Behavior Rating Inventory of Executive Function (BRIEF) self-reported version. As part of the second stage, difficulties in performance or the effects on the various areas of the individual, were evaluated by a questionnaire specifically developed for our clinical research program called the Sociodemographic 
and Clinical Questionnaire for Adults with Attention Deficit/Hyperactivity Disorder (SCQA-ADHD). Finally, in the third stage, each individual case was reviewed by a clinician with at least 15 years' experience (L.P.C.) in ADHD diagnosis and comorbidities. After the full evaluation (the three stages previously described), patients who met the DSM-IV criteria for ADHD were categorically considered cases, while those who did not were considered non-cases. Non-cases may have any disorder but not ADHD.

\section{Interviews and clinimetric instruments}

\section{ADHD Self-reported Rating Scale (ASRS-V1.1)}

This self-report screening questionnaire, developed by the World Health Organization (WHO), is widely used (Kessler et al., 2005; Reyes et al., 2009) to identify ADHD symptoms in adults. This questionnaire was developed from the Composite International Diagnostic Interview (CIDI) (Adler et al., 2006) and is available in two versions. The long version consists of 18 questions corresponding to the DSMIV criteria, which are related to the common manifestations of ADHD in adults. The short version includes the first six questions (section A), which constitute the most predictive symptoms of ADHD (Kessler et al., 2005).

Section A of the ASRS has shown that it has a better psychometric behavior than the 18 -item version in terms of sensitivity $(68.7 \%$ vs. $56.3 \%)$, specificity $(99.5 \%$ vs. $98.3 \%$ ), accuracy in diagnostic classification $(97.9 \%$ vs. 96.2\%) and clinical concordance with the diagnostic standard (Kappa, .76 vs. .58). The test-retest reliability of the full scale showed a Pearson Coefficient greater than .80 (Kessler et al., 2005). The Spanish version of the scale, which differs from the original method of rating with the template, establishes that the diagnostic threshold using section A alone establishes a cut-off point of 12 points, obtaining a sensitivity of $96.7 \%$, a specificity of $91.1 \%$, a positive predictive value of $91.6 \%$, a negative predictive value of $96.5 \%$, a Kappa index of .88 and an area under the curve of .94 (OR $=297.3 ; 95 \% \mathrm{CI}[76.2,1.159])$. This provides further evidence of the advantages of section A of the ASRS as a useful tool for adult screening in a clinical context. Finally, ASRS V1.1 has proved its psychometric properties in various cultures with different cut-off points (Aragonès, Cañisá, Caballero, \& Piñol-Moreso, 2013; Kessler et al., 2007; Ramos-Quiroga et al., 2009; Yeh, Gau, Kessler, \& $\mathrm{Wu}, 2008)$.

Schedule for Affective Disorders and Schizophrenia for School Aged Children Present and Lifetime DSM-IV/Spanish version (Kiddie SADS PL)

The K-SADS-PL interview is a semi-structured, diagnostic interview based on the diagnostic criteria of the DSM -III_R and DSM-IV, which is useful for the cross-sectional and longitudinal clinical assessment of the onset of psychopathology in childhood and adolescence. The Spanish version of the K-SADS-PL has been adapted and validated in the clinical population (Ulloa et al., 2006). The inter-rater reliability study showed that the Kappa coefficients were maintained within the range of good to excellent for the current and lifetime mental health disorders evaluated, especially for ADHD; the Kappa coefficient obtained was .91. For our study, the K-SADS-PL was only used to increase the diagnostic accuracy of ADHD, and was determined as the diagnostic standard in our sample of respondents.

Sociodemographic and Clinical Questionnaire for Adults with Attention Deficit/ Hyperactivity Disorder (SCQA-ADHD)

In order to obtain information that could help us determine the difficulties in performance in various areas of the individual, a questionnaire was specifically designed for our study. The SCQA is a self-report questionnaire specifically designed by researchers in this program (SOL, AJM, PMV, and LPC) for our research program comprising 71 binary questions developed on the basis of scientific evidence, which includes different aspects related to: a) Academic area, b) Working area, c) Risk Behaviors area, d) Social area, e) Economic area, f) Mental health area, and g) Self/-perception. Each of the items in this questionnaire was framed as a Yes/No question.

International Neuropsychiatric Interview for adults, plus version (MINI-plus)

The MINI-plus interview is the long version of the structured psychiatric diagnostic clinical interview for subjects over 18, jointly developed and validated in the United States and Europe for psychiatric disorders included in the fourth version of the diagnostic and statistical manual (DSM-IV) and the tenth international classification of diseases ICD-10 (Sheehan et al., 1997). This interview includes 23 diagnoses, and provides diagnostic exclusion questions, to sub-typify disorders, locate them chronologically by investigating the age of onset, thereby allowing hierarchical exclusions in the event that a patient has more than one disorder over time. For this research, this interview was used to determine comorbidity with the main mental health disorders of all the subjects in the clinical sample (Kumar, Faden, \& Steer, 2011).

Inventory of behavioral evaluation of the Executive Functions (BRIEF self-reported version)

This instrument, designed by Gioia, Isquith, Guy, and Kenworthy (2000), evaluates executive performance in various areas (inhibition, shifting, emotional control, initiation, working memory, planning and organization, self-monitoring, organization of materials and task-monitoring) which presents with a reliability of .91 (Jarratt, Riccio, \& Siekierski, 2005). It has two versions, a self-applicable one and 
one to be completed by an observer, preferably a close relative or a person living with the patient. The adult version contains 75 items and takes approximately 10 minutes to complete. For this study, we decided to use the self-applied version (BRIEF-A), due to its greater availability. The instrument is designed on the basis of a Likert scale, which yields raw scores that are subsequently converted to $\mathrm{T}$ scores. In this report we considered as a $\mathrm{T}$ score $\leq 65$ as the cutoff point. This instrument ranks the result by showing the global score, called the composite global executive index (GEC), which comprises the sum of the scores of two sub-indices called Behavioral Regulation Index (BRI), and Metacognitive Index (MI). The BRI consists of four clinical scales called inhibition, shifting, emotional control and self-monitoring while the MI comprises five scales: starting an activity- initiating-, working memory, planning and organization, task monitoring, and organization of materials. This instrument has shown adequate validity and reliability. The BRIEF has been used in other countries for the concurrent validation of instruments that measure executive function such as the FLEC scale (The Frontal Lobe / Executive Control Scale) and the set of instruments called BASC (Behavior Assessment System for Children [Parent Rating Scales]) (Sullivan \& Riccio, 2006). Lastly, its clinical utility in the evaluation of executive functions has been demonstrated in individuals with a range of health conditions in various age groups (Ciszewski, Francis, Mendella, Bissada, \& Tasca, 2014; Cummings, Singer, Krieger, Miller, \& Mahone, 2002; Mahone, Cirino, et al., 2002; Mahone, Zabel, Levey, Verda, \& Kinsman, 2002; Shear, del Bello, Lee, Rosenberg, \& Strakowski, 2002).

\section{Statistical analysis}

Initially, the values lost for each variable were replaced through the simple imputation method (Papageorgiou, Grant, Takkenberg, \& Mokhles, 2018), provided the maximum value lost was $15 \%$ for each given variable. No variable amounted to $10 \%$ of lost values. Once the previous step had been completed, the distribution of the data was evaluated through the Kolmogorov-Smirnov test. We considered distribution to be normal when the $p$ value was $>.05$ (Wallot \& Leonardi, 2018).

In keeping with the objectives of our study, for the univariate or descriptive analysis of the categorical variables of the study such as sociodemographic variables, comorbid mental disorders, executive functions, psychosocial functioning, proportions and frequency distributions were used. For the bivariate analysis, in the case of the categorical variables, $\chi^{2}$ and Fisher's exact tests were used through $2 \times 2$ tables and for the continuous variables, student $T$ tests were used for independent samples. Unadjusted odds ratios $(O R)$ and their $95 \%$ confidence interval (CI) was calculated. The diagnostic status of ADHD was determined as an independent variable. The main dependent variables were the symptomatology and clinical manifestations associated with ADHD, comorbid psychiatric disorders established according to DSM-IV, difficulties in various areas of functioning of adults and difficulties in executive functions according to BRIEF, $p$ value $<.05$ was considered statistically significant. We used the SPSS program version 19.

\section{RESULTS}

\section{Demographic and clinical characteristics of the study sample}

The study sample included 151 subjects, $54.6 \%(n=82)$ of whom had ADHD. Nearly $66 \%$ of the overall sample were women, with a mean age of 29.7 years ( $S D$ 6.6 years), who also had a mean of two psychiatric disorders $(S D$ 1.2).

\section{Demographic and clinical characteristics of adults with and without ADHD}

There were no differences in the proportion of women with and without ADHD (70.7\% vs. $59.4 \%$ respectively, $O R=.6 ; 95 \% \mathrm{CI}[.3,1.2] ; p=.146)$. The average age in the group with ADHD was significantly lower than that of those who did not present with the diagnosis (28.1 SD 6.1 vs. $31 S D$ 7, respectively). Within the group with ADHD, $79.3 \%(n=65)$ had at least one comorbid disorder. The average number of comorbid disorders was significantly higher in the group of adults with ADHD compared to the group without the disorder ( $2.5 S D 1.1$ vs. $1.3 S D 1.0$ respectively; $F=.439 ; t=-6.621 ; g l=149 ; p<.001)$. Only dysthymia had a significantly higher frequency in subjects with ADHD compared with those who did not have it $(19.5 \%$ vs $2.9 \%, O R=8.1 ; 95 \%$ CI $[1.8,36.7])$ (Table 1$)$.

\section{Report of associated symptoms in adults with and without ADHD}

When using the MINI Interview-ADHD Module to distinguish between clinical manifestations in childhood and adulthood, we only found that adults with ADHD reported having more difficulties in emotional regulation during their childhood $(67.1 \%$ vs. $49.3 \%$ respectively, $O R=2.1 ; 95 \%$ CI[1.1, 4.1]), which was no longer statistically significant in adulthood ( $89.0 \%$ vs. $79.7 \%$ respectively, $O R=2.1 ; 95 \%$ $\mathrm{CI}[.8,5.1])$ and behavioral problems $(54.9 \%$ vs. $31.9 \%$ respectively, $O R=2.6 ; 95 \% \mathrm{CI}[1.3,5.1])$. Specifically, in the data reported in adult life, we found that subjects with ADHD changed jobs more frequently than those without the disorder ( $45.1 \%$ vs. $29.0 \%$ respectively, $O R=2.0 ; 95 \%$ CI[1.0 to 4.0$])$. The remainder of the information showed no significant differences between groups. 


\section{Report on difficulties in various areas of psychosocial functioning between adults with and without ADHD}

When comparing both groups in the report on difficulties in functioning in different psychosocial spheres (Table 2), we found that adults with ADHD had more difficulties in the workplace. Subjects with ADHD procrastinated more in different activities of their daily lives, had more difficulties organizing their lives and problems managing time and their finances. Finally, in aspects that may affect their performance in daily life, adults with ADHD reported dif-

Table 1

Frequency of psychiatric disorders in adults with or without $A D H D^{\mathrm{a}}$

\begin{tabular}{lccr}
\hline & \multicolumn{2}{c}{ Adults $(n=151)$} & \\
\cline { 2 - 3 } & \multicolumn{2}{c}{ Frequency $(\%)$} & \\
\cline { 2 - 3 } & ADHD & Non ADHD & \\
\cline { 2 - 3 } & $82(54.6)$ & 69 & OR $(95 \% \mathrm{Cl})$ \\
\hline Major Depressive Disorder & $42(51.2)$ & $37(53.6)$ & $.91(.5,1.7)$ \\
Dysthymia* & $16(19.5)$ & $2(2.9)$ & $8.1(1.8,36.7)$ \\
Suicide Behavior & $7(8.5)$ & $5(7.4)$ & $1.2(.4,3.9)$ \\
Generalized Anxiety Disorder & $18(22)$ & $18(26.1)$ & $.8(.4,1.7)$ \\
Panic Attacks & $8(9.8)$ & $7(10.1)$ & $.9(.3,2.8)$ \\
Agoraphobia & $7(8.5)$ & $4(5.8)$ & $1.5(.4,5.4)$ \\
Social Phobia & $3(3.7)$ & $0(.0)$ & $1.1(.9,1.1)$ \\
Posttraumatic Stress Disorder & $1(1.2)$ & $1(1.4)$ & $.8(.1,13.6)$ \\
Alcohol use Disorder & $4(4.9)$ & $6(8.7)$ & $.5(.2,2.0)$ \\
Substance use Disorder & $8(9.8)$ & $6(8.7)$ & $1.1(.4,3.5)$ \\
\hline
\end{tabular}

Note: ${ }^{\mathrm{a}}=\mathrm{MINI}$ International Neuropsychiatric Interview; ${ }^{*} p<.01$.

Table 2

Difficulties reported in different areas of psychosocial functioning in adults with and without $A D H D^{\mathrm{a}}$

\begin{tabular}{|c|c|c|c|c|}
\hline & \multicolumn{2}{|c|}{$\begin{array}{l}\text { Adults }(n=151) \\
\text { Frequency }(\%)\end{array}$} & \multirow[b]{2}{*}{$z$} & \multirow[b]{2}{*}{ OR $(95 \% \mathrm{Cl})$} \\
\hline & $\begin{array}{c}\text { ADHD } \\
82(54.6)\end{array}$ & $\begin{array}{l}\text { Non ADHD } \\
69(45.4)\end{array}$ & & \\
\hline \multicolumn{5}{|l|}{ Academic area } \\
\hline Difficulties delivering tasks/homework on time ${ }^{\star * *}$ & $70(85.4)$ & $31(44.9)$ & 4.9 & $7.2(3.3,15.5)$ \\
\hline Difficulties estimating the time of your tasks ${ }^{* * *}$ & $71(86.6)$ & $38(55.7)$ & 4.1 & $5.3(2.4,11.6)$ \\
\hline Repeat year & $36(43.9)$ & $34(49.3)$ & .6 & $.8(.4,1.5)$ \\
\hline \multicolumn{5}{|l|}{ Working area } \\
\hline Interpersonal problems & $28(34.1)$ & $24(34.8)$ & .1 & $1.0(.5,1.9)$ \\
\hline Leave things until the last moment*** & $75(91.8)$ & $43(62.3)$ & 4.0 & $6.5(2.6,16.2)$ \\
\hline Difficulties to organize and prioritize tasks ${ }^{* * *}$ & $68(82.9)$ & $32(46.4)$ & 4.6 & $5.6(2.7,11.8)$ \\
\hline Often supported by third parties to improve ${ }^{* *}$ & $57(69.5)$ & $36(52.2)$ & 2.2 & $2.1(1.1,4.1)$ \\
\hline \multicolumn{5}{|l|}{ Risk behaviors area } \\
\hline Transitfines & $23(28.4)$ & $11(15.9)$ & 1.8 & $2.05(.9,4.6)$ \\
\hline Driving accidents & $28(34.2)$ & $24(34.8)$ & .1 & $.97(.5,1.9)$ \\
\hline \multicolumn{5}{|l|}{ Social area } \\
\hline $\mathrm{He}$ is late for any commitment*** & $72(73.5)$ & $31(48.4)$ & 5.2 & $8.8(3.9,19.9)$ \\
\hline Low tolerance to frustration ${ }^{* \star *}$ & $71(86.6)$ & $37(53.6)$ & 4.3 & $5.6(2.5,12.3)$ \\
\hline \multicolumn{5}{|l|}{ Economic area } \\
\hline Impulsive purchases ${ }^{* \star}$ & $51(62.2)$ & $22(31.9)$ & 3.7 & $3.5(1.8,6.9)$ \\
\hline Difficulties in paying debts on time ${ }^{* *}$ & $52(63.4)$ & $24(34.8)$ & 3.5 & $3.3(1.6,6.3)$ \\
\hline \multicolumn{5}{|l|}{ Mental health area } \\
\hline Background psychiatric care & $29(35.4)$ & $22(31.9)$ & .5 & $1.2(.6,2.3)$ \\
\hline \multicolumn{5}{|l|}{ Self / perception } \\
\hline Perception of time & $30(36.6)$ & $25(36.2)$ & .1 & $1.0(.5,2.0)$ \\
\hline It is perceived as incapable compared to others ${ }^{* *}$ & $64(78.4)$ & $35(50.7)$ & 3.5 & $3.5(1.7,7.0)$ \\
\hline They do not value their effort ${ }^{\star *}$ & $71(86.6)$ & $41(59.4)$ & 3.7 & $4.4(2.0,9.8)$ \\
\hline Self-evaluates negatively ${ }^{* * *}$ & $68(82.5)$ & $32(46.4)$ & 4.5 & $5.6(2.7,11.8)$ \\
\hline Difficulties to plan for the future ${ }^{* *}$ & $68(82.5)$ & $36(52.2)$ & 3.9 & $4.5(2.1,9.4)$ \\
\hline
\end{tabular}


Table 3

Comparison of the frequency of reporting difficulties in executive functioning in adults with $A D H D$ and without $A D H D^{\mathrm{a}}$

(Behavior Rating Inventory of Executive Function Adult Version) Self-applicable version: BRIEF-A

\begin{tabular}{|c|c|c|c|c|c|}
\hline & \multicolumn{2}{|c|}{$\begin{array}{l}\text { Adults }(n=151) \\
\text { Frequency }(\%)\end{array}$} & \multirow[b]{2}{*}{$z$} & \multirow[b]{2}{*}{ OR } & \multirow[b]{2}{*}{$95 \% \mathrm{Cl}$} \\
\hline & $\begin{array}{c}\text { ADHD } \\
\text { Frequency (\%) } \\
82(54.6)\end{array}$ & $\begin{array}{l}\text { Non ADHD } \\
\text { Frequency (\%) } \\
69(45.4)\end{array}$ & & & \\
\hline Inhibition & $70(85.4)$ & $6(8.7)$ & 7.8 & 61.3 & $21.7,172.8$ \\
\hline Shifting & $61(74.4)$ & $2(2.9)$ & 6.0 & 97.3 & $21.9,432.3$ \\
\hline Emotional control & $58(70.7)$ & $1(1.4)$ & 4.9 & 164.3 & $21.6,1252.3$ \\
\hline Initiate & $59(72.0)$ & $1(1.4)$ & 4.9 & 174.4 & $22.9,1331.2$ \\
\hline Working memory & $74(90.2)$ & $5(7.2)$ & 8.0 & 118.4 & $36.9,380.1$ \\
\hline Planning and organization & $55(67.1)$ & $2(2.9)$ & 5.6 & 68.2 & $15.5,299.8$ \\
\hline Self-Monitoring & $77(93.9)$ & $8(11.6)$ & 7.8 & 39.1 & $15.6,98.4$ \\
\hline Organization of materials & $61(74.7)$ & $4(5.8)$ & 6.7 & 47.2 & $15.3,145.4$ \\
\hline Task-Monitoring & $69(84.1)$ & $6(8.7)$ & 7.7 & 55.7 & $20.0,155.5$ \\
\hline
\end{tabular}

Note: ${ }^{a}=$ Measured by the instrument evaluation inventory of the executive functioning of the adult version; ${ }^{*} p<.001$.

ficulties planning their future and negative self-evaluation more frequently.

\section{Perceived executive functioning among adults with and without ADHD}

Regarding executive functions evaluated through the BRIEF self-report questionnaire, we found that the group of adults with ADHD had a higher level of executive dysfunction compared to those without the disorder (Table 3). Moreover, adults in the ADHD group reported more difficulties in the behavior regulation index $(86.6 \%$ vs. $5.8 \%$ respectively, $O R=104.9 ; 95 \% \mathrm{CI}[31.8,345.7] ; z=7.65)$ and the metacognitive index ( $85.4 \%$ vs. $5.8 \%$ respectively, $O R=94.79 ; 95 \% \mathrm{CI}[29.10,308.76] ; z=7.56)$ than those without ADHD. As expected, a difference was also observed in the global executive functioning index between groups $(87.8 \%$ vs. $4.3 \%$ respectively, $O R=158.40 ; 95 \%$ CI[1.78, 600.57]; $z=7.45)$.

\section{DISCUSSION AND CONCLUSION}

This research allowed us to describe the clinical and neurocognitive characteristics of an adult sample with and without ADHD. In line with previous research, we found no differences in ADHD diagnosis between men and women (Agnew-Blais et al., 2016; Moffitt et al., 2015). A recent report by Ahnemark et al. (2018) on a Swedish adult population with a recent diagnosis of ADHD, indicated that 57\% of the sample was female. Our finding sheds light on the fact that regardless of gender, people have the same risk of developing ADHD. Moreover, many studies (Caye et al., 2016; Moffitt et al., 2015) reported that in adulthood, the ratio of sex distribution observed in those with childhood onset, changes to a higher ratio for women with this disorder, although this does not mean that being a female is a risk factor for persistence (Caye et al., 2016).

It has been demonstrated that having ADHD throughout life has a negative impact on general health and mental health. It is a risk factor for presenting with other comorbid disorders in mental health (Kessler et al., 2006; Nierenberg et al., 2005) and diseases (Cortese et al., 2016; Liao, Lien, Wang, Huang, \& Chen, 2016), even at an earlier age (Dunne, Hearn, Rose, \& Latimer, 2014; Meinzer et al., 2013; Nierenberg et al., 2005). In our ADHD group, more than three quarters of the study sample had at least one comorbidity; and a higher average of comorbid disorders than those without ADHD. In this regard, in a study published by Polyzoi, Ahnemark, Medin, and Ginsberg(2018), based on the Swedish national register of patients, $52.6 \%$ of adults with ADHD had at least one comorbidity, mainly anxiety disorders, substance use disorders and affective disorders. Our findings support the scientific evidence that having ADHD is related to more severe clinical symptoms than in those who do not have the diagnosis (Barkley \& Brown, 2008; Nierenberg et al., 2005).

When they suspect ADHD, mental health professionals must consider that the clinical expression of adult symptoms can be modified by the environment in such a way that the patient must be analyzed on the basis of the context in which s/he develops. In this respect, ADHD models, including DSM-5 (American Psychiatric Association, 2013; Steinhausen, 2009), a) describe hyperactivity as a ubiquitous/ universal behavior, b) predict that hyperactivity decreases throughout development, and inattention persists' or c) differentiate between subtypes/ presentations according to perceived differences in hyperactive behavior or in- 
attention. However, recent scientific data indicates that both hyperactivity/impulsivity and inattention in subjects with ADHD can be significantly influenced by environmental factors and cognitive/ executive functioning demands (Kofler, Raiker, Sarver, Wells, \& Soto, 2016).

Since the current DSM-5 diagnostic criteria for ADHD is based on findings from the pediatric population (Applegate et al., 1997; Lahey et al., 1994), proper diagnostic criteria for adults is essential. The growing scientific evidence reported in recent decades has contributed to the concept and understanding of ADHD, which is at a stage of theoretical rethinking, from the initial notion of a specific form of brain dysfunction to a concept that includes variables such as neurodevelopment, a concept which involves the evaluation of symptoms throughout life (Almeida et al., 2013; Shaw, Gogtay, \& Rapoport, 2010; Shaw et al., 2013), gene-environment interaction (Steinhausen, 2009), consideration of age of onset (Agnew-Blais et al., 2016; Moffitt et al., 2015), and clinical aspects. All of these leads us to consider that ADHD is a heterogeneous group of related phenotypic expressions (Taylor, 2009).

In our study, adults with ADHD reported difficulties in emotional regulation in childhood, and nine out of ten persisted with this problem in adulthood. There is currently a discussion about whether this psychopathological characteristic should be part of the clinical description of ADHD (Retz, Stieglitz, Corbisiero, Retz-Junginger, \& Rosler, 2012) in children and adolescents as well as adults. Several empirical studies have confirmed a high prevalence of emotional dysregulation in adults, coupled with a reported frequency of central symptoms of inattention, hyperactivity, and impulsivity (Hirsch, Chavanon, Riechmann, \& Christiansen, 2018).

Adults with ADHD versus those without ADHD have more difficulties in different areas of functioning. This finding adds to the accumulated scientific evidence on the clear relationship between ADHD and executive functioning (Antshel et al., 2010; Nigg et al., 2005; Seidman, 2006; Stavro, Ettenhofer, \& Nigg, 2007). Adults with persistent symptoms reported more difficulties related with to executive functions, involving controlled attention, rather than hyperactivity and impulsivity symptoms (Barkley, 2008). Deficits in executive control that appear in the early stages of life of subjects with ADHD tend to persist into adulthood and are consistent with the reports of both the patient and informants, with respect to the behavioral manifestations of executive dysfunctions in everyday life (Barkley, 2012; Grane, Endestad, Pinto, \& Solbakk, 2014; Karam et al., 2009).

Subjects with ADHD procrastinate more than subjects without the disorder. Procrastination is defined as the tendency to delay activities that must be completed before a deadline. Several psychosocial interventions designed for adults with ADHD include the treatment of procrastina- tion, but there is very little information about its relationship with ADHD. In fact, procrastination is not officially recognized as a symptom related to this disorder. A recent study of 54 college students found that only inattention correlated with procrastination, once the hyperactivity/ impulsivity domain had been corrected for (Niermann \& Scheres, 2014).

This research contributes to the study of ADHD in adulthood in a Latin American population. To our knowledge, this is one of the first studies of a Mexican clinical population, obtained from a research program located at Mexico's INPRFM, whose main objective is the early detection and study of ADHD throughout life. Among the strengths of this study we can say that we confirmed or ruled out the presence of this neurodevelopmental disorder through a semistructured clinical interview undertaken by an experienced clinician. The limitations in this study, included the fact that executive dysfunction in adults with ADHD was based on a self-report, rather than performance. Convenience sampling was carried out, which reduces the possibility of generalizing results to other clinical populations. Sample size was small, and we did not have healthy controls to contrast our findings. These limitations imply the need to directly evaluate executive functions not only in a self report but with neuropsychological batteries and to use controlled samples rather than convenience samples.

As expected, adults with ADHD versus those without this neurodevelopmental disorder, but with other disorders such as anxiety or depression, were associated with different outcomes and clinical variables related to a more severe, dysfunctional clinical presentation. Special attention must be paid when evaluating women since they have the same risk of developing the disorder, particularly in adulthood. Subjects with ADHD had more comorbidities, were more likely to have difficulties in various psychosocial areas and therefore a more severe prognosis. As reported in previous studies, our research showed that ADHD in adulthood is associated with various executive and non-executive difficulties. Future studies in this sample will help us to understand the clinical course of adults with this neurodevelopmental disorder.

\section{Funding}

None.

\section{Conflict of interest}

In the past year, Dr. Francisco de la Peña Olvera received income, travel expenses continuing education support and research support from Shire, Springer Edit. and the Consejo Nacional de Ciencia y Tecnologia in Mexico. Dr. Lino Palacios Cruz is a speaker at Novartis and Shire, serves on the Novartis advisory board and received income, travel expenses and continuing education support from Shire. The remaining authors declare they have no conflict of interest. 


\section{REFERENCES}

Adler, L. A., Spencer, T., Faraone, S. V., Kessler, R. C., Howes, M. J., Biederman, J., \& Secnik, K. (2006). Validity of pilot Adult ADHD Self- Report Scale (ASRS) to Rate Adult ADHD symptoms. Annals of Clinical Psychiatry, 18(3), 145-148.

Agnew-Blais, J. C., Polanczyk, G. V., Danese, A., Wertz, J., Moffitt, T. E., \& Arseneault, L. (2016). Evaluation of the Persistence, Remission, and Emergence of Attention-Deficit/Hyperactivity Disorder in Young Adulthood. JAMA Psychiatry, 73(7), 713-720. doi: 10.1001/jamapsychiatry.2016.0465

Ahnemark, E., di Schiena, M., Fredman, A. C., Medin, E., Soderling, J. K., \& Ginsberg, Y. (2018). Health-related quality of life and burden of illness in adults with newly diagnosed attention-deficit/hyperactivity disorder in Sweden. BMC Psychiatry, 18(1), 223. doi: 10.1186/s12888-018-1803-y

Almeida, L. G., Friederichsen, A., Olivia, A., Rodríguez, R., de la Peña, F., \& Cortés, J. (2006). Construction, validity and reliability, of the screening scale "FASCT" for attention deficit hyperactivity disorder in adults (self-reported and observer versions). Actas españolas de psiquiatría, 34(4), 231-238.

Almeida, L. G., Prado, H., Martínez, R. B., de la Torre, L. B., Avila, D., \& Duarte, M. G. (2013). Brain cortical thickness in ADHD: Age, sex, and clinical correlations. Journal of Attention Disorders, 17(8), 641-654. doi: 10.1177/1087054711434351

American Psychiatric Association. (2013). Diagnostic and statistical manual of mental disorders: DSM-5. Arlington: American Psychiatric Association.

Antshel, K. M., Faraone, S. V., Maglione, K., Doyle, A. E., Fried, R., Seidman, L. J., \& Biederman, J. (2010). Executive functioning in high-IQ adults with ADHD. Psychological Medicine, 40(11), 1909-1918. doi: 10.1017/S0033291709992273

Applegate, B., Lahey, B. B., Hart, E. L., Biederman, J., Hynd, G. W., Barkley, R. A., ... Shaffer, D. (1997). Validity of the age-of-onset criterion for ADHD: A report from the DSM-IV field trials. Journal of the American Academy of Child \& Adolescent Psychiatry, 36(9), 1211-1221.

Aragonès, E., Cañisá, A., Caballero, A., \& Piñol-Moreso, J. L. (2013). Screening for attention deficit hyperactivity disorder in adult patients in primary care. Revista de Neurología, 56(9), 449-455.

Asherson, P., Buitelaar, J., Faraone, S. V., \& Rohde, L. A. (2016). Adult attention-deficit hyperactivity disorder: key conceptual issues. The Lancet Psychiatry, 3(6), 568-578. doi: 10.1016/s2215-0366(16)30032-3

Barkley, R. A. (2012). Distinguishing sluggish cognitive tempo from attention-deficit/hyperactivity disorder in adults. Journal of Abnormal Psychology, 121(4), 978-990. doi: 10.1037/a0023961

Barkley, R. A. (2008). Challenges in diagnosing adults with ADHD. The Journal of Clinical Psychiatry, 69(12), e36.

Barkley, R. A. \& Brown, T. E. (2008). Unrecognized attention-deficit/hyperactivity disorder in adults presenting with other psychiatric disorders. CNS spectrums, 13(11), 977-984.

Biederman, J. (1998). Attention-deficit/hyperactivity disorder: A life-span perspective. The Journal of clinical psychiatry, 59(7), 4-16.

Biederman, J., Faraone, S., Milberger, S., Curtis, S., Chen, L., Marrs, A., ... \& Spencer, T. (1996). Predictors of persistence and remission of ADHD into adolescence: Results from a four-year prospective follow-up study. Journal of the American Academy of Child \& Adolescent Psychiatry, 35(3), 343-351. doi: 10.1097/00004583-199603000-00016

Biederman, J. (2005). Attention-deficit/hyperactivity disorder: a selective overview. Biological Psychiatry, 57(11), 1215-1220. doi: 10.1016/j.biopsych.2004.10.020

Biederman, J. \& Faraone, S. V. (2005). Attention-deficit hyperactivity disorder. The Lancet, 366(9481), 237-248.

Caye, A., Rocha, T. B., Anselmi, L., Murray, J., Menezes, A. M., Barros, F. C., ... \& Rohde, L. A. (2016). Attention-Deficit/Hyperactivity Disorder Trajectories From Childhood to Young Adulthood: Evidence From a Birth Cohort Supporting a Late-Onset Syndrome. JAMA Psychiatry, 73(7), 705-712. doi: 10.1001/ jamapsychiatry.2016.0383

Ciszewski, S., Francis, K., Mendella, P., Bissada, H., \& Tasca, G. A. (2014). Validity and reliability of the behavior rating inventory of executive function - adult version in a clinical sample with eating disorders. Eating Behaviors, 15(2), 175181. doi: 10.1016/j.eatbeh.2014.01.004

Cortese, S., Moreira-Maia, C. R., st. Fleur, D., Morcillo-Penalver, C., Rohde, L. A., \& Faraone, S. V. (2016). Association Between ADHD and Obesity: A Systemat- ic Review and Meta-Analysis. American Journal of Psychiatry, 173(1), 34-43. doi: 10.1176/appi.ajp.2015.15020266

Cummings, D. D., Singer, H. S., Krieger, M., Miller, T. L., \& Mahone, E. M. (2002). Neuropsychiatric effects of guanfacine in children with mild tourette syndrome: a pilot study. Clinical Neuropharmacology, 25(6), 325-332.

Dunne, E. M., Hearn, L. E., Rose, J. J., \& Latimer, W. W. (2014). ADHD as a risk factor for early onset and heightened adult problem severity of illicit substance use: An accelerated gateway model. Addictive behaviors, 39(12), 1755-1758. doi: 10.1016/j.addbeh.2014.07.009

Faraone, S. V., Biederman, J., Doyle, A., Murray, K., Petty, C., Adamson, J. J., \& Seidman, L. (2006). Neuropsychological studies of late onset and subthreshold diagnoses of adult attention-deficit/hyperactivity disorder. Biological psychiatry, 60(10), 1081-1087. doi: 10.1016/j.biopsych.2006.03.060

Fayyad, J., De Graaf, R., Kessler, R., Alonso, J., Angermeyer, M., Demyttenaere, K., ... Jin, R. (2007). Cross-national prevalence and correlates of adult attention-deficit hyperactivity disorder. The British Journal of Psychiatry, 190(5), 402-409.

Gioia, G. A., Isquith, P. K., Guy, S. C., \& Kenworthy, L. (2000). TEST REVIEW Behavior Rating Inventory of Executive Function. Child Neuropsychology, 6(3), 235-238. doi: 10.1076/chin.6.3.235.3152

Grane, V. A., Endestad, T., Pinto, A. F., \& Solbakk, A. K. (2014). Attentional control and subjective executive function in treatment-naive adults with Attention Deficit Hyperactivity Disorder. PLoSOne, 9(12), e115227. doi: 10.1371/journal. pone. 0115227

Hirsch, O., Chavanon, M., Riechmann, E., \& Christiansen, H. (2018). Emotional dysregulation is a primary symptom in adult Attention-Deficit/Hyperactivity Disorder (ADHD). Journal of affective disorders, 232, 41-47. doi: 10.1016/j. jad.2018.02.007

Jarratt, K. P., Riccio, C. A., \& Siekierski, B. M. (2005). Assessment of Attention Deficit Hyperactivity Disorder (ADHD) Using the BASC and BRIEF. Applied Neuropsychology, 12(2), 83-93. doi: 10.1207/s15324826an1202_4

Karam, R., Bau, C. H., Salgado, C. A., Kalil, K. L., Victor, M. M., Sousa, N. O., ... \& Grevet, E. H. (2009). Late-onset ADHD in adults: Milder, but still dysfunctional. Journal of Psychiatric Research, 43(7), 697-701. doi: 10.1016/j. jpsychires.2008.10.001

Kessler, R. C., Green, J. G., Adler, L. A., Barkley, R. A., Chatterji, S., Faraone, S. V., ... \& Russo, L. J. (2010). Structure and diagnosis of adult attention-deficit/ hyperactivity disorder: analysis of expanded symptom criteria from the Adult ADHD Clinical Diagnostic Scale. Archives of General Psychiatry, 67(11), 1168-1178. doi: 10.1001/archgenpsychiatry.2010.146

Kessler, R. C., Adler, L. A., Gruber, M. J., Sarawate, C. A., Spencer, T., \& Van Brunt, D. L. (2007). Validity of the World Health Organization Adult ADHD Self-Report Scale (ASRS) Screener in a representative sample of health plan members. International journal of methods in psychiatric research, 16(2), 52-65. doi: $10.1002 / \mathrm{mpr} .208$

Kessler, R. C., Adler, L., Barkley, R., Biederman, J., Conners, C. K., Demler, O., ... \& Zaslavsky, A. M. (2006). The prevalence and correlates of adult ADHD in the United States: Results from the National Comorbidity Survey Replication. American Journal of Psychiatry, 163(4), 716-723.

Kessler, R. C., Adler, L., Ames, M., Demler, O., Faraone, S., Hiripi, E., ... \& Walters, E. E. (2005). The World Health Organization Adult ADHD Self-Report Scale (ASRS): A short screening scale for use in the general population. Psychological Medicine, 35(2), 245-256.

Kofler, M. J., Raiker, J. S., Sarver, D. E., Wells, E. L., \& Soto, E. F. (2016). Is hyperactivity ubiquitous in ADHD or dependent on environmental demands? Evidence from meta-analysis. Clinical psychology review, 46, 12-24. doi: 10.1016/j.cpr.2016.04.004

Kooij, S. J., Bejerot, S., Blackwell, A., Caci, H., Casas-Brugué, M., Carpentier, P. J., ... \& Asherson, P. (2010). European consensus statement on diagnosis and treatment of adult ADHD: The European Network Adult ADHD. BMC Psychiatry, 10(1), 67 .

Kumar, G., Faden, J., \& Steer, R. A. (2011). Screening for attention-deficit/hyperactivity disorder in adult inpatients with psychiatric disorders. Psychological reports, 108(3), 815-824. doi: 10.2466/03.05.09.13.15.pr0.108.3.815-824

Lahey, B. B., Applegate, B., McBurnett, K., Biederman, J., Greenhill, L., Hynd, G. W., ... \& Garfinkel, B. (1994). DMS-IV field trials for attention deficit hyperac- 
tivity disorder in children and adolescents. The American Journal of Psychiatry, 151(11), 1673-1685. doi: 10.1176/ajp.151.11.1673

Langley, K., Fowler, T., Ford, T., Thapar, A. K., van den Bree, M., Harold, G., ... \& Thapar, A. (2010). Adolescent clinical outcomes for young people with attention-deficit hyperactivity disorder. The British Journal of Psychiatry, 196(3), 235-240. doi: 10.1192/bjp.bp.109.066274

Lasser, R. A., Goodman, D. W., \& Asherson, P. (2012). Lifespan persistence of ADHD: the life transition model and its application. Journal of Clinical Psychiatry, 73(2), 192-201.

Lara, C., Fayyad, J., de Graaf, R., Kessler, R. C., Aguilar-Gaxiola, S., Angermeyer, M., ... \& Sampson, N. (2009). Childhood predictors of adult attention-deficit/ hyperactivity disorder: results from the World Health Organization World Mental Health Survey Initiative. Biological Psychiatry, 65(1), 46-54.

Liao, T. C., Lien, Y. T., Wang, S., Huang, S. L., \& Chen, C. Y. (2016). Comorbidity of Atopic Disorders with Autism Spectrum Disorder and Attention Deficit/Hyperactivity Disorder. The Jounal of Pedriatics, 171, 248-255. doi: 10.1016/j. jpeds.2015.12.063

Mahone, E. M., Cirino, P. T., Cutting, L. E., Cerrone, P. M., Hagelthorn, K. M., Hiemenz, J. R., ... \& Denckla, M. B. (2002). Validity of the behavior rating inventory of executive function in children with ADHD and/or Tourette syndrome. Archives of Clinical Neuropsychology, 17(7), 643-662.

Mahone, E. M., Zabel, T. A., Levey, E., Verda, M., \& Kinsman, S. (2002). Parent and self-report ratings of executive function in adolescents with myelomeningocele and hydrocephalus. Child Neuropsychology, 8(4), 258-270. doi: 10.1076/ chin.8.4.258.13510

Matte, B., Rohde, L. A., \& Grevet, E. H. (2012). ADHD in adults: a concept in evolution. ADHD Attention Deficit and Hyperactivity Disorders, 4(2), 53-62. doi: 10.1007/s12402-012-0077-3

Meinzer, M. C., Lewinsohn, P. M., Pettit, J. W., Seeley, J. R., Gau, J. M., Chronis-Tuscano, A., \& Waxmonsky, J. G. (2013). Attention-deficit/hyperactivity disorder in adolescence predicts onset of major depressive disorder through early adulthood. Depress Anxiety, 30(6), 546-553. doi: 10.1002/da.22082

Moffitt, T. E., Houts, R., Asherson, P., Belsky, D. W., Corcoran, D. L., Hammerle, M., ... Caspi, A. (2015). Is Adult ADHD a Childhood-Onset Neurodevelopmental Disorder? Evidence From a Four-Decade Longitudinal Cohort Study. al cohort study. American Journal of Psychiatry, 172(10), 967-977. doi: 10.1176/appi. ajp.2015.14101266

Nierenberg, A. A., Miyahara, S., Spencer, T., Wisniewski, S. R., Otto, M. W., Simon, N., ... \& Sachs, G. S. (2005). Clinical and diagnostic implications of lifetime attention-deficit/hyperactivity disorder comorbidity in adults with bipolar disorder: data from the first 1000 STEP-BD participants. Biolodical Psychiatry, 57(11), 1467-1473. doi: 10.1016/j.biopsych.2005.01.036

Niermann, H. C. \& Scheres, A. (2014). The relation between procrastination and symptoms of attention-deficit hyperactivity disorder (ADHD) in undergraduate students. International journal of methods in psychiatric research, 23(4), 411421. doi: $10.1002 / \mathrm{mpr} \cdot 1440$

Nigg, J. T., Stavro, G., Ettenhofer, M., Hambrick, D. Z., Miller, T., \& Henderson, J. M. (2005). Executive functions and ADHD in adults: evidence for selective effects on ADHD symptom domains. Journal of Abnormal Psychology, 114(4), 706-717.

Papageorgiou, G., Grant, S. W., Takkenberg, J. J. M., \& Mokhles, M. M. (2018). Statistical primer: how to deal with missing data in scientific research? Interactive cardiovascular and thoracic surgery, 27(2), 153-158. doi: 10.1093/icvts/ivy102

Polanczyk, G., Rohde, L. A., Szobot, C., Schmitz, M., Montiel-Nava, C., \& Bauermeister, J. J. (2008). ADHD treatment in Latin America and the Caribbean. Journal of the American Academy of Child \& Adolescent Psychiatry, 47(6), 721-722.

Polanczyk, G., de Lima, M. S., Horta, B. L., Biederman, J., \& Rohde, L. A. (2007). The worldwide prevalence of ADHD: a systematic review and metaregression analysis. American journal of psychiatry, 164(6), 942-948.
Polanczyk, G. \& Rohde, L. A. (2007). Epidemiology of attention-deficit/hyperactivity disorder across the lifespan. Current opinion in psychiatry, 20(4), 386-392. doi: 10.1097/YCO.0b013e3281568d7a

Polyzoi, M., Ahnemark, E., Medin, E., \& Ginsberg, Y. (2018). Estimated prevalence and incidence of diagnosed ADHD and health care utilization in adults in Sweden - A longitudinal population-based register study. Neuropsychiatric disease and treatment, 14, 1149-1161. doi: 10.2147/ndt.s155838

Ramos-Quiroga, J. A., Daigre, C., Valero, S., Bosch, R., Gomez-Barros, N., Nogueira, M., ... \& Casas, M. (2009). Validación al español de la escala de cribado del trastorno por déficit de atención/hiperactividad en adultos (ASRS v. 1.1): Una nueva estrategia de puntuación. Revista de Neurología, 48(9), 449-452.

Ramos-Quiroga, J. A., Bosch-Munsó, R., Castells-Cervelló, X., Nogueira-Morais, M., García-Gimenez, E., \& Casas-Brugué, M. (2006). Attention deficit hyperactivity disorder in adults: a clinical and therapeutic characterization. Revista de Neurología, 42(10), 600-606.

Retz, W., Stieglitz, R. D., Corbisiero, S., Retz-Junginger, P., \& Rosler, M. (2012). Emotional dysregulation in adult ADHD: What is the empirical evidence? Expert review of neurotherapeutics, 12(10), 1241-1251. doi: 10.1586/ern.12.109

Reyes, E., Cárdenas, E. M., García, K. L., Aguilar, N. C., Vázquez, J., Díaz, A., ... \& Palacios, L. (2009). Validación de constructo de la escala de autorreporte del Trastorno por Déficit de Atención con Hiperactividad (TDAH) en el adulto de la Organización Mundial de la Salud en población universitaria mexicana. Salud Mental, 32(S1), 69-75.

Seidman, L. J. (2006). Neuropsychological functioning in people with ADHD across the lifespan. Clinical psychology review, 26(4), 466-485. doi: 10.1016/j. cpr.2006.01.004

Shaw, P., Malek, M., Watson, B., Greenstein, D., de Rossi, P., \& Sharp, W. (2013). Trajectories of cerebral cortical development in childhood and adolescence and adult attention-deficit/hyperactivity disorder. Biological Psychiatry, 74(8), 599606. doi: 10.1016/j.biopsych.2013.04.007

Shaw, P., Gogtay, N., \& Rapoport, J. (2010). Childhood psychiatric disorders as anomalies in neurodevelopmental trajectories. Human brain mapping, 31(6), 917-925.

Shear, P. K., delBello, M. P., Lee Rosenberg, H., \& Strakowski, S. M. (2002). Parental reports of executive dysfunction in adolescents with bipolar disorder. Child Neuropsychology, 8(4), 285-295. doi: 10.1076/chin.8.4.285.13511

Sheehan, D. V., Lecrubier, Y., Sheehan, K. H., Janavs, J., Weiller, E., Keskiner, A., ... \& Dunbar, G. C. (1997). The validity of the Mini International Neuropsychiatric Interview (MINI) according to the SCID-P and its reliability. European Psychiatry, 12(5), 232-241.

Stavro, G. M., Ettenhofer, M. L., \& Nigg, J. T. (2007). Executive functions and adaptive functioning in young adult attention-deficit/hyperactivity disorder. Journal of the International Neuropsychological Society, 13(2), 324-334.

Steinhausen, H. C. (2009). The heterogeneity of causes and courses of attention-deficit/hyperactivity disorder. Acta Psychiatrica Scandinavica, 120(5), 392-399.

Sullivan, J. R. \& Riccio, C. A. (2006). An empirical analysis of the BASC Frontal Lobe/Executive Control scale with a clinical sample. Archives of Clinical Neuropsychology, 21(5), 495-501.

Taylor, E. (2009). Developing Adhd. Journal of Child Psychology and Psychiatry, 50(1-2), 126-132.

Ulloa, R. E., Ortiz, S., Higuera, F., Nogales, I., Fresán, A., Apiquian, R., ... \& de la Peña, F. (2006). Interrater reliability of the Spanish version of Schedule for Affective Disorders and Schizophrenia for School-Age Children--Present and Lifetime version (K-SADS-PL). Actas Españolas de Psiquiatría, 34(1), 36-40.

Wallot, S. \& Leonardi, G. (2018). Deriving inferential statistics from recurrence plots: A recurrence-based test of differences between sample distributions and its comparison to the two-sample Kolmogorov-Smirnov test. Chaos, 28(8), 085712. doi: $10.1063 / 1.5024915$

Yeh, C. B., Gau, S. S. F., Kessler, R. C., \& Wu, Y. Y. (2008). Psychometric properties of the Chinese version of the adult ADHD Self-report Scale. International Journal of Methods in Psychiatric Research, 17(1), 45-54. 